\title{
Proposta de um jogo didático para o ensino da conservação de recursos hídricos
}

\author{
Proposal for a teaching game for teaching water resource conservation \\ Propuesta de juego didáctico para enseñar la conservación de recursos hídricos
}

Recebido: 30/05/2021 | Revisado: 07/06/2021 | Aceito: 11/06/2021 | Publicado: 25/06/2021

\author{
Larissa Santos Vieira \\ ORCID: https://orcid.org/0000-0001-9450-9876 \\ Centro Universitário de Volta Redonda, Brasil \\ E-mail: 1.santos.v.19@gmail.com \\ Tatiana Nascimento Docile \\ ORCID: https://orcid.org/0000-0001-8964-5662 \\ Universidade do Estado do Rio de Janeiro, Brasil \\ E-mail: tatidocile@gmail.com \\ André Barbosa Vargas \\ ORCID: https://orcid.org/0000-0002-8340-8217 \\ Centro Universitário de Volta Redonda, Brasil \\ E-mail: andrebvargss@yahoo.com.br \\ Paulo Roberto de Amoretty \\ ORCID: https://orcid.org/0000-0003-4153-6058 \\ Centro Universitário de Volta Redonda, Brasil \\ E-mail: pauloamoretty@yahoo.com.br \\ Aline Silveira-Alves \\ ORCID: https://orcid.org/0000-0002-1946-146X \\ Centro Universitário de Volta Redonda, Brasil \\ E-mail: alinesilveira-alves@hotmail.com \\ Ronaldo Figueiró \\ ORCID: https://orcid.org/0000-0003-0762-1312 \\ Centro Universitário de Volta Redonda, Brasil \\ Fundação Centro Universitário Estadual da Zona Oeste, Brasil \\ Universidade Castelo Branco, Brasil \\ E-mail: ronaldofigueiro@gmail.com
}

\begin{abstract}
Resumo
Diante de tudo que conseguimos compreender da importância das diversas formas de se trabalhar os conteúdos no ensino de ciências e biologia, foi pensada em uma maneira de estudarmos nas aulas de biologia o conteúdo de Ecologia em especial a conservação de recursos hídricos, de forma mais lúdica. Portanto, esse trabalho tem como objetivo a elaboração de um jogo didático sobre o uso da água como recurso, por meio da criação da consciência ecológica e do consumo inteligente para a conservação dos recursos hídricos. Para a realização da construção do jogo didático foi realizada uma coleta de dados sobre a revisão bibliográfica acerca do tema e sobre a criação de jogos didáticos. Neste trabalho o jogo didático desenvolvido foi feito através do conteúdo água, é um jogo de tabuleiro em que os jogadores irão caminhar da saída até a chegada, onde serão utilizados pinos, dados e cartas, no qual o jogador terá perguntas ou então algumas armadilhas, avance casas, volte casas, fique sem jogar uma rodada, entre outros. A perspectiva na utilização desse jogo é ser mais uma forma de aprendizagem sobre o conteúdo água, principalmente em termos de conservação de recursos hídricos onde estaria ajudando ao aluno a criação de uma consciência ecológica e sustentabilidade e fazendo com que se entenda a importância do uso do recurso água. A aplicabilidade do jogo deve ser feita antes ou após a explicação do conteúdo, para alunos do Ensino médio. Desta forma o aluno poderá ter uma memorização melhor do assunto e ter uma mudança de hábitos e pensamentos.
\end{abstract}

Palavras-chave: Recursos hídricos; Jogo didático; Ensino.

\begin{abstract}
In view of all that we can understand of the importance of the different ways of working with the contents in science and biology teaching, a way of studying in the biology classes the content of Ecology, especially the conservation of water resources, was thought of in a more playful way. Therefore, this work aims to develop a didactic game about the use of water as a resource, through the creation of ecological awareness and intelligent consumption for the conservation of water resources. In order to carry out the construction of the didactic game, data were collected on the bibliographic review on the theme and on the creation of didactic games. In this work the didactic game developed was made through the water content, it is a board game in which the players will walk from the exit to the arrival, where pins, dice and cards will be used, in which the player will have questions or some traps, advance houses, return houses, stay without playing a round, among others. The prospect of using this game is to be one more way of
\end{abstract}


learning about water content, especially in terms of conserving water resources where it would be helping the student to create an ecological awareness and sustainability and making the understanding of the importance of using water available. water resource. The applicability of the game must be done before or after explaining the content, for high school students. In this way the student can have a better memorization of the subject and have a change in habits and thoughts.

Keywords: Water resources; Didactic game, Teaching.

\section{Resumen}

En vista de todo lo que podemos entender la importancia de las diferentes formas de trabajar los contenidos en la enseñanza de la ciencia y la biología, se pensó en una forma de estudiar en las clases de biología los contenidos de Ecología, especialmente la conservación del agua. recursos, más lúdico. Por tanto, este trabajo tiene como objetivo desarrollar un juego didáctico sobre el uso del agua como recurso, a través de la creación de conciencia ecológica y consumo inteligente para la conservación de los recursos hídricos. Para llevar a cabo la construcción del juego didáctico, se realizó una recolección de datos sobre la revisión bibliográfica sobre el tema y sobre la creación de juegos didácticos. En este trabajo se realizó el juego didáctico desarrollado a través del contenido de agua, es un juego de mesa en el que los jugadores caminarán desde la salida hasta la llegada, donde se utilizarán pines, dados y cartas, en el cual el jugador tendrá preguntas o algunas trampas, casas de avance, casas de retorno, quedarse sin jugar una ronda, entre otros. La perspectiva de usar este juego es una forma más de aprender sobre el contenido del agua, especialmente en términos de conservación de los recursos hídricos, donde ayudaría al estudiante a crear una conciencia ecológica y sustentable y hacer que la comprensión de la importancia del uso del agua esté disponible. recurso hídrico. La aplicabilidad del juego debe realizarse antes o después de explicar el contenido, para estudiantes de secundaria. De esta forma el alumno puede tener una mejor memorización del tema y tener un cambio de hábitos y pensamientos.

Palabras clave: Recursos hídricos; Juego Didáctico, Enseñanza.

\section{Introdução}

A água é o elemento essencial a todos os seres vivos por ser um componente biogeoquímico com propriedades únicas capaz de solubilizar uma ampla gama de compostos químicos e servir de habitat para muitas espécies. Para o ser humano é, possivelmente, o único recurso natural que tem relação direta com todos os aspectos da sociedade, como o progresso da agricultura; da indústria; os valores culturais e religiosos consolidados na sociedade; como elemento simbólico de valores sociais e culturais; e como fator de produção de inúmeros bens de consumo (Gomes, 2011, Bacci \& Pataca, 2008). O ciclo da água na natureza é fundamental para a manutenção da vida no nosso planeta, visto que irá determinar a variação climática e interferir no nível dos rios, lagos, mares, águas subterrâneas e oceanos (Ricklefs \& Relyea, 1997).

Os recursos hídricos são as águas disponíveis para as atividades humanas. Esses recursos apresentam grande relevância no progresso de diversas atividades econômicas. Em relação à agricultura, a água pode representar até $90 \%$ da composição física das plantas. A falta d’água em períodos de crescimento dos vegetais pode arruinar plantações e até ecossistemas devidamente implantados (Gomes, 2011). Na indústria, para se obter diversos produtos, o volume de água necessário é muitas vezes superior ao volume produzido. A geração de energia, onde no Brasil, a água é a principal fonte de geração de energia elétrica. Consumo doméstico, utilizada em diversas atividades domésticas, como lavar roupas e louças, na alimentação, em fazer comida e beber água, limpeza de quintal e higiene pessoal. Do mesmo modo que está na forma de lazer, em piscinas, cachoeiras, lagos e banhos de mar (Gomes, 2011). Contudo, com tantos usos, deveria se ter a consciência do uso este recurso de forma prudente e racional, evitando o desperdício e a poluição, utilizando meios de recurso consciente da água que é um bem essencial a todos.

Quando refletimos sobre os processos de ensino e aprendizagem de Ciências e Biologia, nos níveis de ensino fundamental e médio, vemos que os processos envolvem conteúdos abstratos e, muitas vezes, de difícil compreensão e, ainda hoje, sofrem influências de uma abordagem tradicional do processo educativo, na qual prevalecem a transmissão-recepção de informações feita pelo professor, a dissociação entre conteúdo e realidade e a memorização do mesmo (Campos, et al., 2002).

O uso dos jogos didáticos na aprendizagem é de grande significância, na medida em que é proposto o estímulo ao interesse do aluno, desenvolvendo níveis diferentes de experiência pessoal e social, ajuda-se na construção de suas novas 
descobertas, desenvolve e enriquece sua personalidade, e simboliza um instrumento pedagógico que leva o professor à condição de condutor, estimulador e avaliador da aprendizagem, não mais como mero transmissor de conhecimento. Podendo ser utilizado como promotor de aprendizagem das práticas escolares, possibilitando a aproximação dos alunos ao conhecimento científico, levando-os a ter uma vivência, mesmo que fictícia, de solução de problemas que são muitas vezes próximas da realidade que o homem enfrenta ou enfrentou (Campos, et al., 2002).

Os jogos didáticos apresentam grande importância no desenvolvimento dos alunos, envolvendo os aspectos cognitivo, afetivo, físico-motor, social, criativo e moral, além de ser uma ferramenta pedagógica para o processo de ensino e de aprendizagem. O jogo pedagógico ou didático é aquele fabricado com o objetivo de proporcionar determinadas aprendizagens e atingir objetivos pedagógicos específicos, diferenciando-se do material pedagógico, por conter o aspecto lúdico (Cunha, 1988), sendo uma alternativa para a evolução no desempenho dos alunos em diversos conteúdos, principalmente aqueles considerados de difícil aprendizagem (Gomes, et al., 2001).

No ensino de Ciências e Biologia, o conteúdo que aborda os recursos hídricos dentro da área de Ecologia é rotineiramente trabalhado de modo tradicional e mecânico, com textos e figuras ilustradas nos livros didáticos, fazendo com que a curiosidade já existente nos alunos sobre diferentes organismos seja prostrada ou perdida. Diante de tudo que conseguimos compreender da importância das diversas formas de se trabalhar os conteúdos, foi pensada em uma maneira de estudarmos nas aulas de biologia o conteúdo de Ecologia em especial a conservação de recursos hídricos, de forma mais lúdica.

O principal responsável pelo uso desenfreado dos recursos hídricos é o homem, e ele não avalia as consequências de seus atos, sofrendo com sua própria ação, o que pode levar a uma futura escassez de água para si próprio e seus semelhantes. É importante abordar essas situações para os estudantes, despertando a vontade de pensar ecologicamente correto. Portanto, o intuito do jogo é criar a consciência ecológica e demonstrar a importância da água de uma forma lúdica para conservação desse recurso hídrico.

Portanto, o presente trabalho tem como objetivo a elaboração de um jogo didático sobre a conservação dos recursos hídricos que permitirá estimular o desenvolvimento de uma consciência ecológica de forma lúdica. Importante não apenas para a conservação de recursos hídricos, mas do meio ambiente como um todo.

\section{Metodologia}

A proposta deste jogo didático foi pautada na coleta de dados por artigos científicos nas bases de periódicos: google acadêmico e scielo. Não houve um recorte temporal específico para essa busca. As palavras-chaves utilizadas para a busca foram "jogos didáticos", "ensino" e "biologia".

Após a coleta dos artigos foi feita uma revisão bibliográfica (Estrela, 2018) sobre os principais e mais relevantes modelos de jogos educacionais utilizados pela comunidade de pesquisadores e professores no ensino de Biologia no ensino médio. Assim, observando o modelo de jogo mais utilizado, o nome do jogo e o nível de ensino para o qual o jogo foi produzido nortearam o formato desta proposta.

Definido o modelo de jogo a ser desenvolvido passamos ao conteúdo a ser abordado. A temática do jogo foi a água como recurso hídrico, visto que, há uma necessidade dos estudantes observarem a analisarem a realidade vivenciada no seu dia-a-dia sobre a conservação de recursos hídricos e nada melhor que um jogo voltado para esta questão (Barros, et al., 2019). 


\section{Resultados e Discussão}

Composto por um tabuleiro, seis barquinhos de papel, oito cartas e um dado com seis faces este estudo apresenta o jogo didático "Conservando e conhecendo os recursos hídricos". Neste jogo poderão ser abordados assuntos diversos de acordo com a temática hídrica. Trata-se de um jogo de tabuleiro em que os jogadores irão "navegar" no leito de um rio. Ao longo do trajeto, do ponto de partida até a chegada, o jogador irá interagir, respondendo a perguntas na tentativa de superar algumas armadilhas como, por exemplo, avance casas, volte casas ou fique sem jogar uma rodada. Vence aquele que completar o trajeto primeiro.

O tabuleiro foi desenhado em um circuito com início e chegada, onde se tem uma trilha, dividida em casas com numeração em vermelho e azul. O tabuleiro (Figura 1) foi desenhado em uma trilha do rio que percorre uma cidade, onde se tem casas, indústrias e áreas florestadas. Os participantes iniciam o jogo no ponto de partida e irão percorrer o tabuleiro através do lançamento do dado e com o seu resultado o andar das casas, até chegarem ao final.

Figura 1: Imagem do tabuleiro do jogo "Conservando e conhecendo os recursos hídricos".

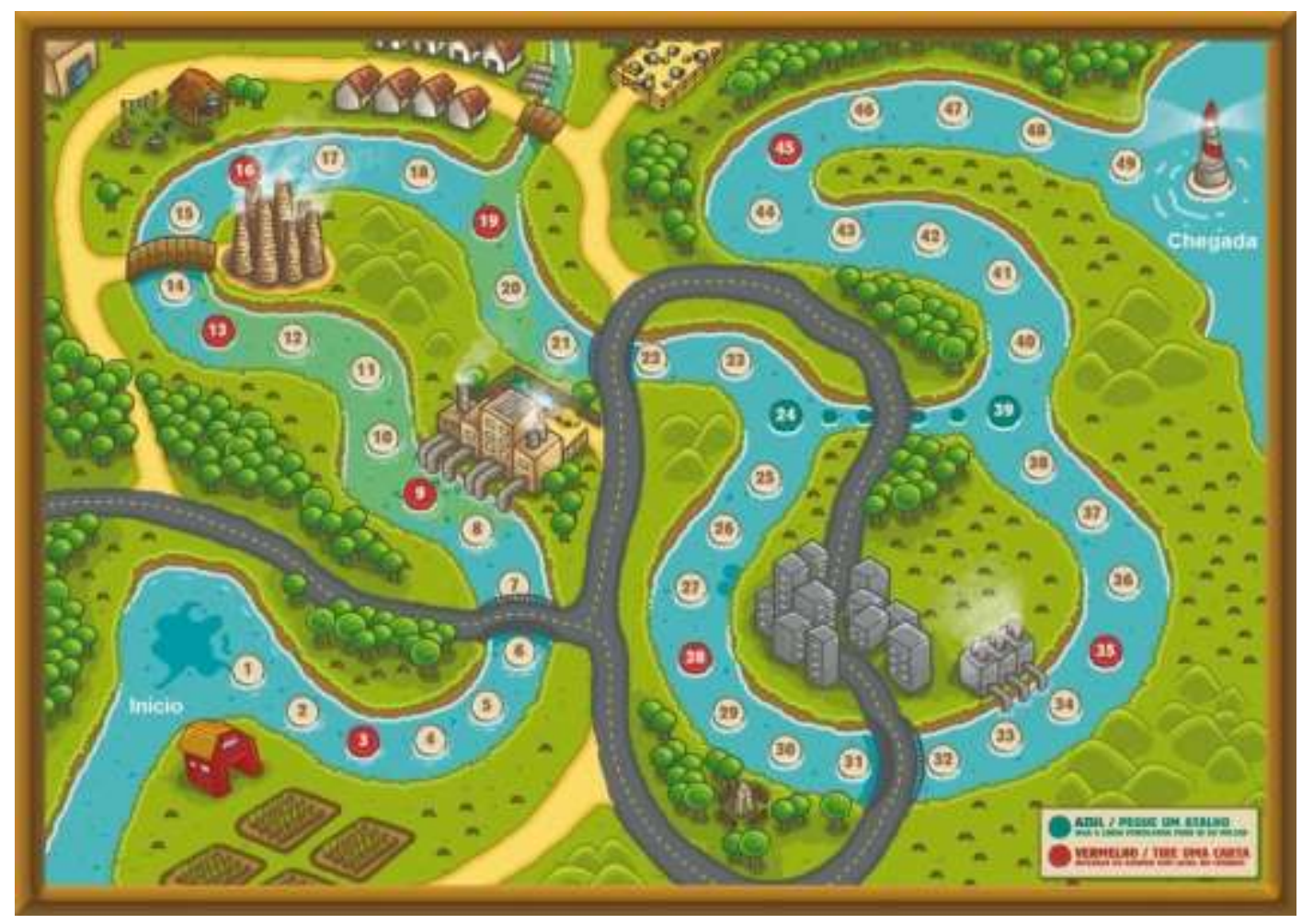

Fonte: Arquivo pessoal.

Ao deslocar seu barco ao longo do trajeto no rio o jogador poderá parar na casa com numeração em vermelho e deverá pegar uma carta; nesta carta terá um avance ou volte casas (Quadro 1), interagindo com o cenário. As cartas (Figura 2) têm sua parte de trás com a parte do cenário do tabuleiro que irão interagir e em cada uma ocorrerá uma ação que poderá ser: ficar uma rodada sem jogar, avançar casas ou voltar casas. 
Quadro 1: Parte da frente das cartas do jogo "Conservando e conhecendo os recursos hídricos".

Plantação Indústria Química

Este agricultor desmatou a mata ciliar do rio para fazer sua plantação. Desta forma ele polui o rio e o deixa sem proteção, podendo ser assoreado. Cite uma maneira de reverter esta situação.

Avance duas casas!

$$
\text { Vilarejo }
$$

Os moradores do vilarejo não estão nem ai para a água. Lavam as calçadas ao invés de varrer, não reutilizam a água da máquina de lavar e não tem esgoto tratado.

Volte três casas!

\section{Você é o dono dessa indústria e ela está descartando produtos químicos e esgoto sem tratamento no rio.}

Isso é crime!!

Volte ao início!
Nessa indústria a água da chuva é reutilizada para molhar o jardim e para as descargas do banheiro.

\section{Parabéns!!}

Avance duas casas!

\section{Desmatamento}

Nesta cidade, todos os moradores são conscientes. Reutilizam a

água da chuva e da máquina de lavar e tem seu esgoto tratado.

Avance três casas!
A mata perto do rio foi toda desmatada, deixando uma nascente desprotegida, desta forma ela pode secar!

Volte duas casas!

\section{Pescador}

O pescador tem consciência da importância da água para ele e para os peixes. Por isso ele reutiliza a água da chuva para molhar as plantas e limpar o quintal.

Avance duas casas!

\section{Pecuária}

Este criador de ovelhas está reflorestando o leito do rio perto de sua criação.

Avance uma casa

Fonte: Arquivo pessoal.

Figura 2: Parte de trás das cartas, correspondentes as áreas de interação do tabuleiro "Conservando e conhecendo os recursos hídricos".

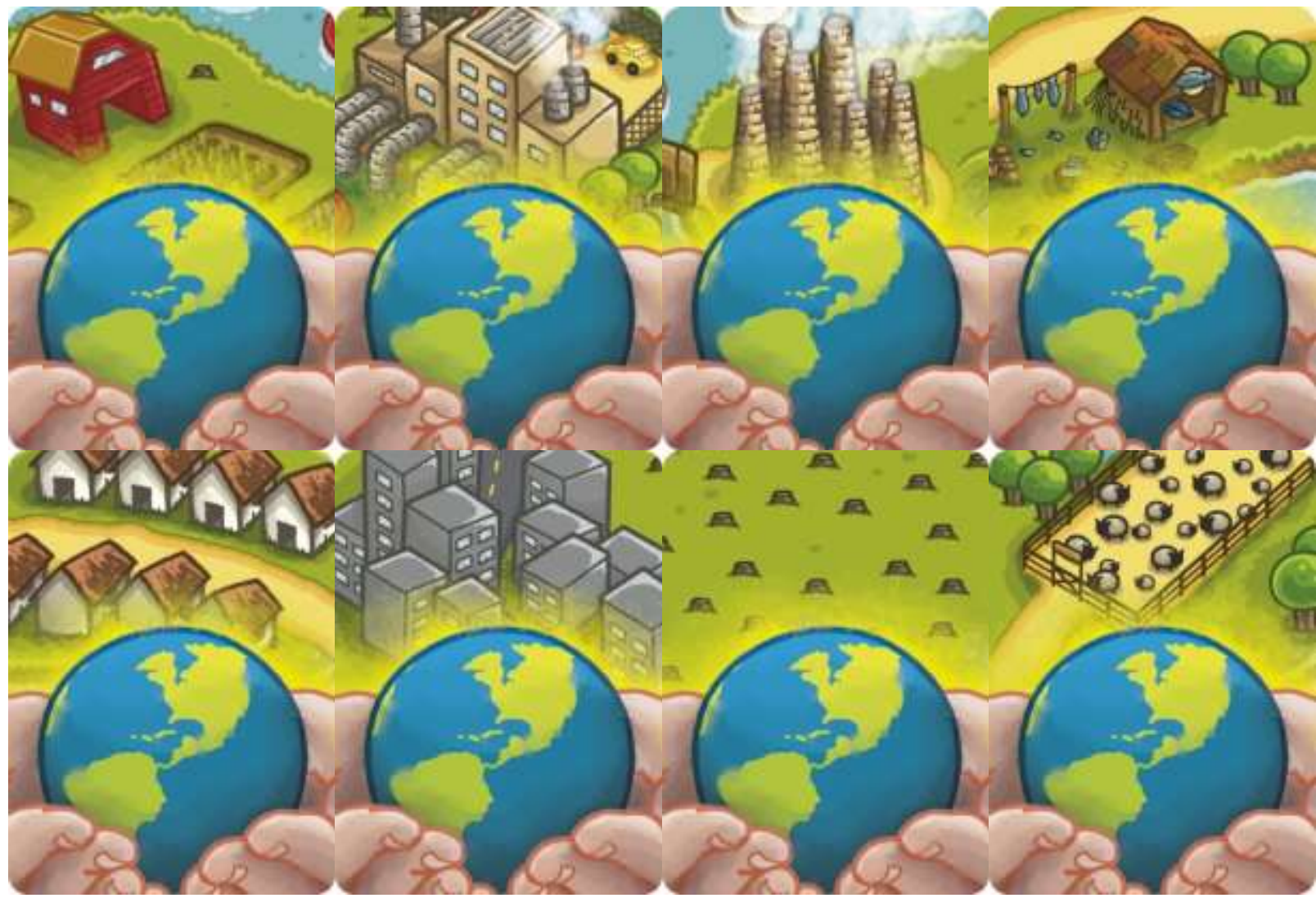

Fonte: Arquivo pessoal. 
Nas casas em que a numeração for azul, que serão as casas 24 e 39, existe um passe rápido ou corta caminho, que pode ser de ir da casa 24 para a 39 ou se o jogador cair na casa 39, voltar para a 24. Os pinos são barquinhos de papel (Figura 3) feitos a mão onde cada jogador poderá confeccionar seu barco da maneira que quiser, podendo personalizá-lo, e eles serão de tamanho pequeno.

Figura 3: Exemplo de barquinho de papel utilizado como peão no jogo.

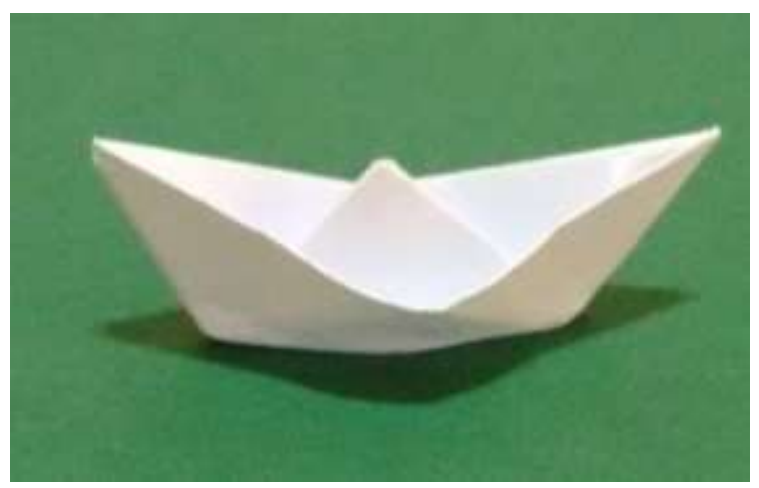

Fonte: Arquivo pessoal.

A palavra jogo originária do latim ludus que significa diversão, brincadeira, demonstra que o jogo didático nada mais é que o aprender brincando. Com isso, o jogo é considerado um instrumento de grande relevância na aprendizagem, devido a sua correlação direta com desenvolvimento social, criativo, afetivo, histórico e cultural do ser humano. Quando se joga, a criança e o adolescente aprende, descobre, inventa, experimenta, desenvolve sua inteligência e suas habilidades sociais e cognitivas (Alves \& Bianchin, 2010).

O jogo pedagógico ou didático tem como objetivo proporcionar determinadas aprendizagens, porém com um aspecto lúdico, onde o aprender está camuflado no brincar, fazendo com que dessa forma se consiga atingir determinados objetivos pedagógicos e sociais, além também de melhorar o desempenho dos alunos, pois muitas vezes matérias em que se apresentam grandes dificuldades, são melhores compreendidas através de uma forma lúdica, onde passada para os livros se torna mais fácil de assimilar (Cunha, 1988, Gomes, et al., 2001).

O presente jogo tem como objetivo ser mais uma forma de aprendizagem sobre o conteúdo água, principalmente em termos de conservação de recursos hídricos onde estaria ajudando ao aluno a criação de uma consciência ecológica e sustentabilidade e fazendo com que se entenda a importância do uso do recurso água. A aplicabilidade do jogo deve ser feita antes ou após a explicação do conteúdo, para alunos do Ensino médio. Desta forma o aluno poderá ter uma memorização melhor do assunto e ter uma mudança de hábitos e pensamento. Visto que aprendendo como economizar a água, muitas vezes em pequenas atitudes como o fechar a torneira ao escovar os dentes, estaremos educando futuros adultos conscientes sobre os recursos naturais e desta forma protegendo por mais tempo este bem tão precioso para nós. Do mesmo modo que partindo das crianças e adolescentes se pode chegar aos seus pais, fazendo com que estes também mudem suas atitudes, afinal, muitas vezes serão chamados atenção por algo de errado que estarão fazendo ou então estarão fazendo o bem para ser exemplo aos filhos.

O preconceito sobre jogos didáticos tem que ser quebrado, pois muitas vezes o uso de um jogo para determinados conteúdos faz com que a aprendizagem e a criação de conhecimento seja melhor do que somente a recepção do conteúdo. Assim, o que é aprendido em sala de aula é posto em prática nestes jogos e esta prática é muito mais eficiente para que se tenha a fixação do conhecimento, do que provas e testes, visto que na maioria das vezes os alunos apenas decoram a matéria no 
intuito de conseguir nota nas provas e não de adquirir conhecimento. Então o jogo didático, gera nos alunos o entusiasmo em aprender de uma forma divertida e muitas vezes desafiadora, e assim a aprendizagem é significativa.

Muitos resultados são atingidos por meio do uso de jogos didáticos, dentre eles os principais são: os relacionados à cognição, que seriam o desenvolvimento da inteligência e da personalidade, elementos fundamentais para a construção do conhecimento; a afeição que seria o desenvolvimento da sensibilidade, da empatia e da afetividade; a socialização que seria o bom convívio em grupo e a perda de individualidade; e a motivação que seria a ação, a iniciativa, o desafio, a curiosidade e a criatividade (Miranda, 2001).

A utilização do jogo didático pelo professor faz com que ele crie uma maior proximidade com seus alunos, gerando uma melhor interação professor-aluno e que muitas vezes melhora significativamente, o convívio dos alunos dentro e fora de sala.

\section{Conclusão}

O uso de jogos, enquanto ferramentas didáticas, pode proporcionar aos estudantes um aprendizado mais agradável por meio do lúdico, de forma que os conceitos acabam sendo internalizados de uma forma divertida, porém duradoura. O uso do jogo proposto nesse artigo pode ter um papel facilitador da aprendizagem, complementando as aulas expositivas e fazendo com que o estudante tenha uma experiência imersiva neste tema.

\section{Referências}

Alves, L.\& Bianchin, M. A. (2010). O jogo como recurso de aprendizagem. Rev. Psicopedagogia; 27(83): 282-7.

ANA. Agência Nacional de Águas. (2018) Panorama das águas. http://www3.ana.gov.br/portal/ANA/panorama-das-aguas/agua-no-mundo ANA. Agência Nacional de Águas. (2018) Águas no Brasil. http://www3.ana.gov.br/portal/ANA/aguas-no-brasil/panorama-das-aguas/quantidade-da-agua. Azevedo Netto, J. M. (1959). Cronologia dos serviços de esgotos, com especial menção ao Brasil. Revista DAE, 20(33):15-19.

Barros, M.G., Miranda, J. C. \& Costa, R. C. (2019) Uso de jogos didáticos no processo ensino-aprendizagem. Revista Educação Pública, 19(23).

Brasil. (2000) Secretaria de Educação Fundamental. Parâmetros Curriculares Nacionais. Rio de Janeiro: DP\&A, v. 3 e 2.

Bacci, D. C. \& Pataca, E. M. (2008) Educação para Água. Estudos Avançados, 22 (63).

Bortoloto, T. M.; Felício, A. K. C. (2003) A Produção de jogos didáticos para o ensino de ciências e biologia: uma proposta para favorecer a aprendizagem. Cadernos dos Núcleos de Ensino, São Paulo, p. 35-48.

Caponera, D. (1992). Principles of Water Law and Administration: national and international. Rotterdam: Balkema.

Cunha, N. (1988). Brinquedo, desafio e descoberta. Rio de Janeiro: FAE.

Estrela, C. (2018). Metodologia Científica: Ciência, Ensino, Pesquisa. Editora Artes Médicas.

Friedmann, A. (1996). Brincar: crescer e aprender, o resgate do jogo infantil. São Paulo: Moderna.

Fialho, N. N. (2008) Os jogos pedagógicos como ferramenta de ensino. www.moodle.ufba.br/file.php/8823/moddata/.../jogos_didaticos.pdf.

Girard, J. M. (1908) Éducation de la petite enface. Paris: Librairie Armand Colin.

Gomes, M. A. F. (2011) Água: sem ela seremos o planeta Marte de amanhã. Embrapa, março.

Gomes, R. R. \& Friedrich, M. A. (2001) Contribuição dos jogos didáticos na aprendizagem de conteúdos de Ciências e Biologia. In: EREBIO,1, Rio de Janeiro, Anais..., Rio de Janeiro, p.389-92.

Liebmann, H., (1979). Terra, um planeta inabitável: da antiguidade, até os nossos dias, toda a trajetória poluidora da humanidade. Rio de Janeiro: Biblioteca do Exército.

Pato, J. H. (2008). O valor da Água como bem Público. Tese de doutoramento em Cências Sociais (Especialidade: Sociologia Geral), apresentada à Universidade de Lisboa, através do Instituto de Ciências Sociais.

Piaget, J. (1976) Psicologia e pedagogia. Trad. Lindoso DA, Ribeiro da Silva RM. Rio de Janeiro: Forense Universitária. 
Research, Society and Development, v. 10, n. 7, e38010716645, 2021

(CC BY 4.0) | ISSN 2525-3409 | DOI: http://dx.doi.org/10.33448/rsd-v10i7.16645

Projeto Brasil das águas. (2018) A Importância da Água. http://brasildasaguas.com.br/educacional/a-importancia-da-agua.

Ricklefs, R. \& Relyea, R. (2018) A Economia da Natureza. Revisão técnica - Cecília Bueno; Tradução Ana Cláudia de Macêdo Vieira ... [et al.]. - 7. ed. [Reimpr.]. - Rio de Janeiro: Guanabara Koogan.

Silva, E. R. da. (1998) O Curso da Água na História: Simbologia, Moralidade e a Gestão de Recursos Hídricos. Tese de doutorado, apresentada à Fundação Oswaldo Cruz, Escola Nacional de Saúde Pública. 